\title{
Protective Effects of Alpha-Lipoic Acid on Oleic Acid-Induced Acute Lung Injury in Rats
}

\author{
Funda Gülcü Bulmuş ${ }^{1}$, Mehmet Ferit Gürsu², Mehmet Hamdi Muz ${ }^{3}$, İhsan Yaman ${ }^{4}$, Özgür Bulmuş5 ${ }^{5}$ Fatih Sakin ${ }^{6}$ \\ ${ }^{1}$ Vocational School of Health Services, Fırat University, Elazığ, Turkey \\ ${ }^{2}$ Department of Biochemistry, Fırat University Faculty of Medicine, Elazı̆̆, Turkey \\ ${ }^{3}$ Department of Pulmonary Diseases, Fırat University Faculty of Medicine, Elazığ, Turkey \\ ${ }^{4}$ Sivrice Vocational School, Fırat University, Elazığ, Turkey \\ ${ }^{5}$ Veterinary Control Institute, Ministry of Agriculture, Elazı̆̆, Turkey \\ ${ }^{6}$ Department of Pharmacology and Toxicology, Mustafa Kemal University Faculty of Veterinary Medicine, Hatay, Turkey
}

\begin{abstract}
Background: Oxidative stress is believed to be an important factor in the pathogenesis of acute lung injury (ALI).

Aims: The aim of this study was to investigate the possible protective role of alpha-lipoic acid ( $\alpha$-LA) on oleic acid (OA)-induced ALI in rats.

Study Design: Animal experiment.
\end{abstract}

Methods: A total of thirty-five rats were divided into five groups in the study. Group 1 served as a control group. Rats in Group 2 ( $\alpha$-LA) were administered $\alpha$-LA intraperitoneally at a dose of $100 \mathrm{mg} / \mathrm{kg}$ body weight (BW). Rats in Group $3(\mathrm{OA})$ were administered OA intravenously at a dose of 100 $\mathrm{mg} / \mathrm{kg}$ BW. In Group 4 (pre-OA- $\alpha$-LA), $\alpha$-LA was given 15 minutes prior to OA infusion, and in Group 5 (post-OA- $\alpha$-LA), $\alpha$-LA was given two hours after OA infusion. Four hours after the OA infusion, rats were decapitated. Blood samples were collected to measure serum levels of malondialdehyde (MDA) and glutathione (GSH), and the levels of activity for superoxide dismutase (SOD), catalase (CAT) and glutathione peroxidase (GSH-Px). Lung tissue samples were taken for histopathological examination.

Results: Exposure to OA resulted in increases in serum MDA levels $(p<0.001)$, as well as histopathological lesions in lung tissue, and decreases in CAT $(p<0.05)$, GSH-Px $(p<0.05)$ activities and GSH $(p<0.05)$ levels. On the other hand, MDA levels were decreased significantly $(p<0.001)$, while CAT $(p<0.05), G S H-P x(p<0.01)$ activities and GSH $(p<0.05)$ levels were increased significantly in the pre-OA- $\alpha$-LA group compared with the OA group.

Conclusion: $\alpha$-LA was found to lessen oxidative stress and to have positive effects on antioxidants in cases of OA-induced ALI. In conclusion, $\alpha$-LA appears to have protective effects against ALI and potential for the prevention of ALI.

Key Words: Acute lung injury, oleic acid, $\alpha$-lipoic acid, oxidative stress

Received: 25.12 .2012

Accepted: 24.04 .2013

\section{Introduction}

Acute lung injury (ALI) and acute respiratory distress syndrome (ARDS) are characterised by hypoxemia that is resistant to oxygen therapy, decreased lung compliance, increased microvascular permeability, and the presence of diffuse alveolar damage and alveolar oedema $(1,2)$. ALI and ARDS are diffuse responses of the lung to various clinical conditions including trauma, aspiration, sepsis, endotoxemia, and pneumonia. Despite the introduction of new treatment techniques and recent advancements in intensive care technology, the mortality rate of patients with ARDS remains high $(3,4)$. The main anomaly in ARDS is the disruption of the alveolar-capillary barrier. The common characteristics of this syndrome are diffuse interstitial and alveolar oedema, increased microvascular permeability, persistent hypoxemia, and diffuse inflammation $(4,5)$. ARDS is considered an exaggerated inflammatory reaction of the lung to various stimuli, such as pneumonia, aspiration, inhalation, emboli, sepsis, and disseminated intravascular coagula- tion. In these clinical conditions leading to ARDS, increased neutrophil migration to the lungs and activation of inflammatory mediators are observed. Neutrophils cause cell damage by secreting free radicals, inflammatory mediators, proteases (elastase and collagenase), and cytokines such as tumor necrosis factor- $\alpha$ (TNF- $\alpha$ ) (6). The pathogenesis of ALI and ARDS involves multiple mechanisms including oxidant-induced inflammatory damage to the alveolar wall. Recent studies have aimed to prevent or reduce the progression of $\operatorname{ALI}(7,8)$.

Oleic acid (OA; cis-9-octadecanoic acid) is a fatty acid present in animal- and plant-derived oils. When administered intravenously, OA induces morphological and cellular changes similar to those produced by ALI and ARDS in humans. Thus, OA administration is commonly used to generate an experimental model of ALI for the assessment of potential therapeutic agents against ARDS (9-11). Following OA administration, an initial pulmonary vascular endothelial cell injury gives rise to subsequent inflammation and ALI. Numerous studies have reported the following indicators of this oxido-inflammatory state: degeneration of the alveocapillary 
membrane structure, increased alveocapillary permeability, build-up of intra-alveolar and interstitial fluid, haemorrhage, infiltration of polymorphonuclear leukocytes, activation of oxidant enzymes, secretion of cytokines, and the production of adhesion molecules, reactive oxygen species (ROS), and reactive nitrogen species (9-12).

Alpha-lipoic acid ( $\alpha$-LA; 1,2-dithiolane-3-pentanoic acid, 6,8-dithio-octanoic acid, thioctic acid) is a strong antioxidant that plays an essential role as a cofactor in the metabolism of all organisms, from microorganisms to humans $(13,14)$. Because $\alpha$-LA has been found to be effective in the treatment of various models of oxidative stress, it represents a potential therapeutic possibility for many diseases associated with oxidative stress, such as ischemia-perfusion injury, diabetes, cataract formation, HIV activation, neurodegeneration, and radiation damage (14).

The aim of this study was to examine the possible protective effects of $\alpha$-LA treatment on oxidant-antioxidant status and histopathological changes in a commonly used, OA-induced experimental model of ALI. We also aimed to evaluate the effectiveness of $\alpha$-LA, which may be useful in many oxidative stress models, in the treatment of $A L I$ and ARDS.

\section{Material and Methods}

\section{Chemicals}

OA was purchased from Sigma-Aldrich (St. Louis, MO, USA). $\alpha$-LA was obtained from MP Biomedicals Inc. (Solon, $\mathrm{OH}$, USA). Glutathione (GSH) and GSH reductase, thiobarbituric acid (TBA), phosphotungstic acid, hydrogen peroxide $\left(\mathrm{H}_{2} \mathrm{O}_{2}\right)$, nitroblue tetrazolium (NBT), nicotinamide adenine dinucleotide phosphate (NADPH), and other reagents were supplied by Sigma-Aldrich (St. Louis, MO, USA) or Merck (Darmstadt, Germany).

OA was dissolved in ethanol and then diluted to $25 \mathrm{mg} /$ $\mathrm{mL}$ as a final concentration using $0.9 \% \mathrm{NaCl}$ (The final ratio of ethanol:saline was 1:9). The prepared solution was infused intravenously (i.v.) into the tail vein for 5 minutes through a 24 G branula $(15,16)$.

$\alpha$-LA was dissolved in a physiological saline solution containing $0.5 \% \mathrm{NaOH}$, and the $\mathrm{pH}$ of the solution was adjusted to 7.4 with $\mathrm{HCl}$. A dose of $100 \mathrm{mg} / \mathrm{kg} \alpha$-LA was administered intraperitoneally (i.p.) to the rats (17).

\section{Animals and experimental design}

The protocol for animal use was approved by the Institutional Review Board of the National Institute of Health and the Local Committee on Animal Research. The animals were obtained from the Experimental Research Centre of Firat University, Elazığ, Turkey, and maintained under standard laboratory conditions $\left(24 \pm 3^{\circ} \mathrm{C}, 40-60 \%\right.$ humidity, $12 / 12 \mathrm{~h}$ light/dark cycle). A commercial pellet diet (Elazig Food Company, Elazig, Turkey) and fresh drinking water were provided ad libitum.

Thirty-five female Wistar albino rats weighing between 140 and $160 \mathrm{~g}$ were used in the study. The rats were randomly divided into five groups, with seven rats in each group.
The experimental groups were arranged as follows:

Group 1 (control group) received a control solution of physiological saline/ethanol at a dose of $100 \mathrm{mg} / \mathrm{kg} \mathrm{BW}$ via i.v. Group 2 ( $\alpha$-LA group) was given $\alpha$-LA at a dose of $100 \mathrm{mg} /$ kg BW via i.p.

Group 3 (OA group) was given OA at a dose of $100 \mathrm{mg} /$ kg BW via i.v.

Group 4 (pre-OA- $\alpha$-LA group) was administered $\alpha$-LA 15 minutes before OA infusion.

Group 5 (post-OA- $\alpha$-LA group) was administered $\alpha$-LA two hours after OA infusion.

\section{Sample preparation}

Four hours after OA infusion, the rats in each group were decapitated, and blood samples were collected in regular biochemistry tubes. The tubes were centrifuged at $3000 \mathrm{rpm}$ for 10 minutes, and the serum was recovered and kept at $-20^{\circ} \mathrm{C}$ until analysis. Lung samples for later histopathological examination were also removed from the rats and provided in $10 \%$ formaldehyde to the pathology laboratory.

\section{Biochemical analysis}

Malondialdehyde (MDA), the final product of lipid peroxidation, was measured using a spectrophotometric TBA assay adapted from Satoh (18) and Yagi (19). The results are expressed as $\mathrm{nmol} / \mathrm{mL}$.

Superoxide dismutase (SOD) activity in the serum was assessed using the method of Durak et al. (20), modified from Sun et al. (21), which measures the reduction of NBT by superoxide generated with the xanthine/xanthine oxidase system. One unit of SOD activity is defined as the amount of enzyme that inhibits NBT reduction by $50 \%$. The results are expressed as $\mathrm{U} / \mathrm{mL}$.

Serum catalase (CAT) activity was determined by the method described by Aebi (22), during which the decomposition of $\mathrm{H}_{2} \mathrm{O}_{2}$ is followed using spectrophotometry. The results are expressed as $\mathrm{k} / \mathrm{mL}$.

Serum GSH peroxidase (GSH-Px) activity was measured using the method described by Paglia de Valentine (23), in which oxidation of NADPH is spectrophotometrically measured as a decrease in absorbance at $340 \mathrm{~nm}$. The results are expressed as $\mathrm{U} / \mathrm{mL}$.

Serum GSH levels were determined using the dithionitrobenzoic acid recycling method developed by Ellman (24). The results are expressed as $\mathrm{nmol} / \mathrm{mL}$.

\section{Histopathological examination}

The tissue samples from the rats were fixed in a $10 \%$ formaldehyde solution. Following routine preparation, samples were embedded in paraffin blocks using established methods. Sections measuring $5 \mu \mathrm{m}$ were obtained from the blocks, stained with haematoxylin-eosin, and imaged by light microscopy.

\section{Statistical analysis}

All values are presented as the mean \pm standard deviation. The normality analysis of the data was performed using the Kolmogorov-Smirnov test; and the Levene's test was used to analyse the homogeneity of variances. Since all of the data were normally distributed and the variances were homog- 
enous, one-way analysis of variance (one-way ANOVA) was used and followed by post hoc Tukey HSD test, which is a more sensitive test than other post hoc tests, to compare differences between the means of measured biochemical parameters among the experimental groups. Differences were considered significant at $p<0.05$.

\section{Results}

Serum concentrations of MDA and GSH, and activity levels of SOD, CAT, and GSH-Px measured for the different groups are summarised in Table 1. The level of MDA in serum samples from the OA group was increased compared with that of the control group $(p<0.001)$. However, the MDA level in pre-OA- $\alpha$-LA samples was found to be lower than that in OA samples $(p<0.001)$. When compared with samples from the control group, samples from the $\alpha$-LA group exhibited increased CAT and GSH-Px activity levels $(p<0.001$ and $p<0.05$, respectively); in contrast, samples from the OA group exhibited decreased activity levels in the serum $(p<0.05)$. Notably, the activity levels of CAT and GSH-Px in pre-OA- $\alpha$-LA samples were greater than the activity levels in OA samples $(p<0.05$ and $p<0.01$, respectively). Compared with control samples, the serum level of GSH was increased in $\alpha$-LA samples $(p<0.05)$ but decreased in OA samples $(p<0.05)$. However, the serum GSH level in pre-OA$\alpha$-LA samples was greater than the GSH level in OA samples $(p<0.05)$. No significant difference in serum SOD activity was observed among the groups.

Lung samples from the control and $\alpha$-LA groups were histologically normal (Figure 1a), and minimal perivascular infiltration by mononuclear cells was observed in $\alpha$-LA samples (Figure 1b). In contrast, samples from the OA group displayed diffuse alveolar damage including increased vascular permeability, interstitial intra-alveolar oedema and haemorrhage, perivascular and intra-alveolar hyaline membrane formation, and dense interstitial intra-alveolar infiltration by mononuclear cells (Figure 2a and $2 b$ ).

Samples from the pre-OA- $\alpha$-LA group also displayed the presence of perivascular interstitial mononuclear cell infiltration. In addition, congestion and mild haemorrhage were observed in some of the vessels. However, the impairments and mononuclear cell infiltration present in pre-OA- $\alpha-L A$ samples were minor compared with those in OA samples. Additionally, whereas increased vascular permeability, oedema, and hyaline membrane formation were common in OA samples, these injuries were not present in pre-OA- $\alpha$-LA samples (Figure $3 a$ and $3 b$ ).

Table 1. Serum MDA and GSH levels and SOD, CAT, GSH-Px activities of the groups $(n=7)$

\begin{tabular}{|c|c|c|c|c|c|}
\hline & $\begin{array}{l}\text { Group } 1 \\
\text { (Control) }\end{array}$ & $\begin{array}{c}\text { Group } 2 \\
(\alpha-L A)\end{array}$ & $\begin{array}{c}\text { Group } 3 \\
\text { (OA) }\end{array}$ & $\begin{array}{c}\text { Group } 4 \\
\text { (pre-OA- } \alpha-L A)\end{array}$ & $\begin{array}{c}\text { Group } 5 \\
\text { (post-OA- } \alpha-L A)\end{array}$ \\
\hline MDA (nmol/mL) & $0.86 \pm 0.10$ & $0.76 \pm 0.05$ & 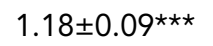 & $0.94 \pm 0.06^{t+t}$ & $1.09 \pm 0.04$ \\
\hline $\mathrm{SOD}(\mathrm{U} / \mathrm{mL})$ & $9.33 \pm 1.08$ & $9.71 \pm 0.97$ & $8.28 \pm 1.06$ & $8.90 \pm 0.59$ & $8.42 \pm 0.68$ \\
\hline CAT (k/mL) & $2.17 \pm 0.20$ & $3.12 \pm 0.56^{\star \star \star}$ & $1.66 \pm 0.23^{\star}$ & $2.23 \pm 0.20^{\dagger}$ & $2.06 \pm 0.25$ \\
\hline GSH-Px (U/mL) & $1.96 \pm 0.15$ & $2.21 \pm 0.18^{\star}$ & $1.75 \pm 0.06^{*}$ & $2.01 \pm 0.09^{\dagger \dagger}$ & $1.82 \pm 0.11$ \\
\hline $\mathrm{GSH}(\mathrm{nmol} / \mathrm{mL})$ & $11.37 \pm 1.66$ & $13.62 \pm 1.66^{*}$ & $9.21 \pm 0.54 *$ & $11.24 \pm 1.02^{\dagger}$ & $10.50 \pm 1.11$ \\
\hline \multicolumn{6}{|c|}{$\begin{array}{l}{ }^{\star} p<0.05 \text {, compared with control group; }{ }^{\star \star} p<0.01 \text {, compared with control group; }{ }^{\star \star \star} p<0.001 \text {, compared with control group. } \\
{ }^{+} p<0.05 \text { compared with OA group; }{ }^{+\dagger} p<0.01 \text {, compared with OA group; }{ }^{++t} p<0.001 \text {, compared with OA group. }\end{array}$} \\
\hline \multicolumn{6}{|c|}{$\begin{array}{l}\text { MDA: malondialdehyde; SOD: superoxide dismutase; CAT: catalase; GSH: glutathione; GSH-Px: glutathione peroxidase; } \\
\alpha \text {-LA: alpha-lipoic acid; OA: oleic acid. }\end{array}$} \\
\hline
\end{tabular}

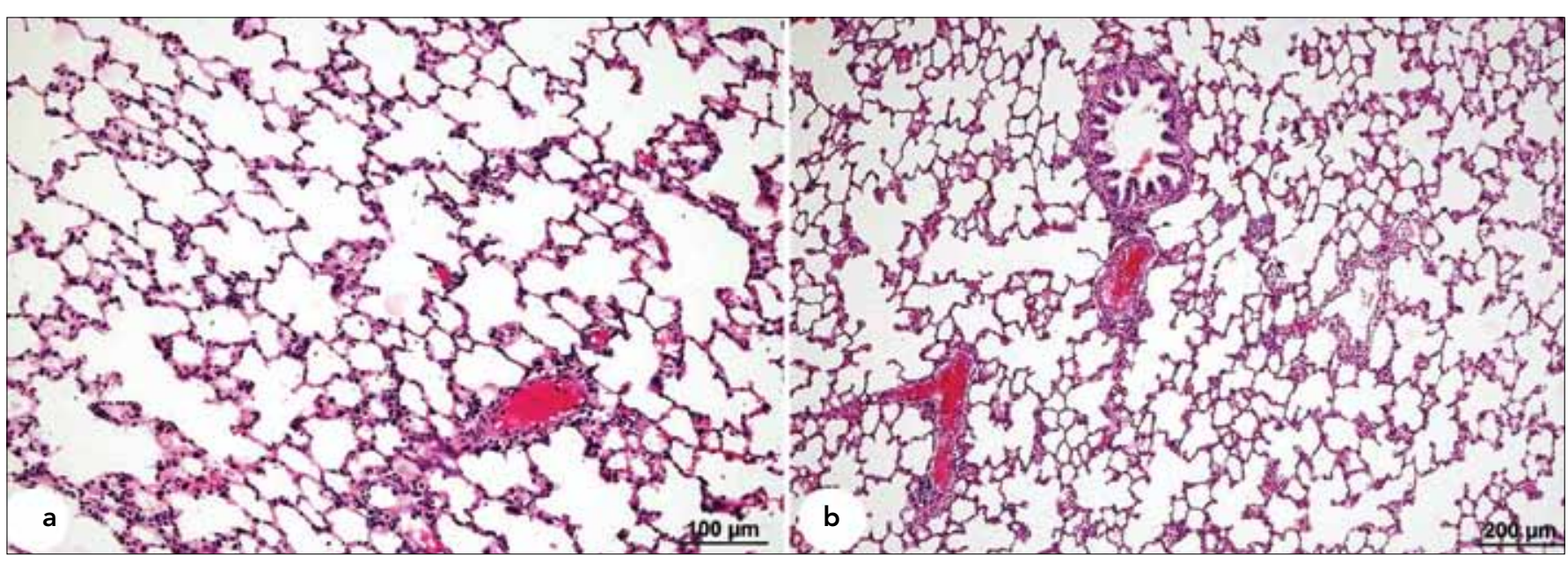

Figure 1. a, b. Histopathological HE staining of samples from the control and $\alpha$-LA groups. Normal lung histology in control samples (a). Minimal perivascular infiltration by mononuclear cells $\alpha$-LA samples (b). 


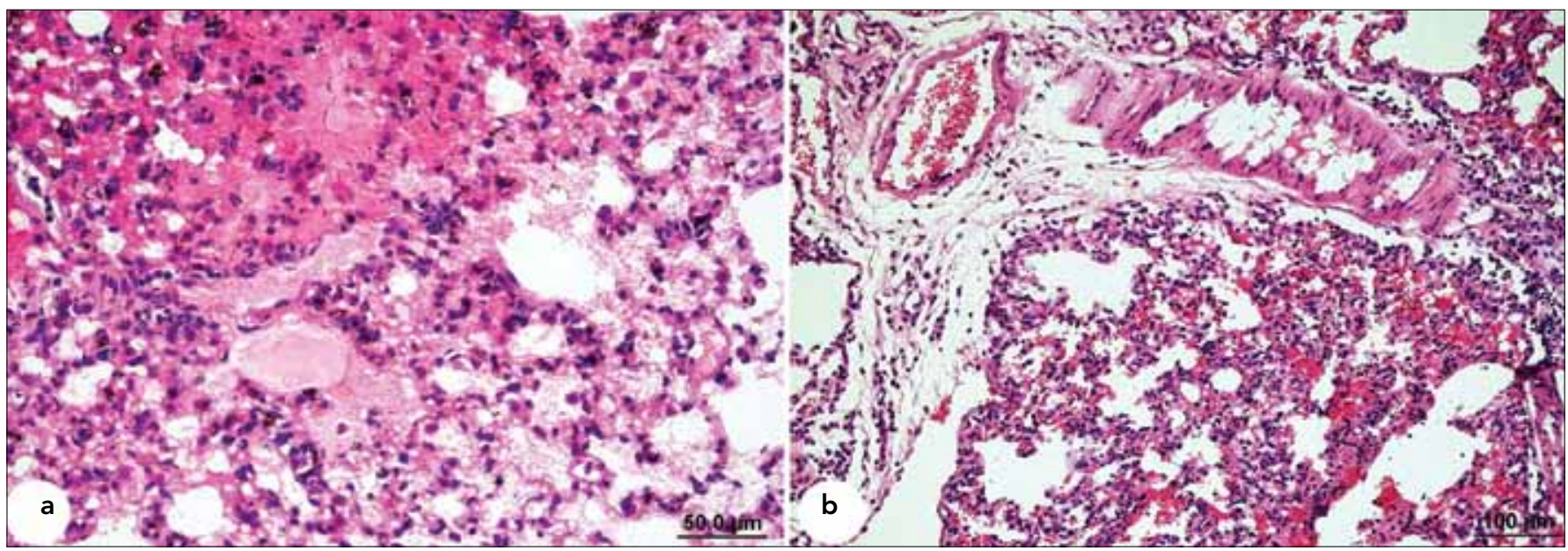

Figure 2. a, b. Histopathological HE staining of samples from the OA group. Interstitial intra-alveolar oedema, haemorrhage, and diffuse hyaline membrane formation (a). Perivascular oedema and interstitial intra-alveolar infiltration by mononuclear cells (b).

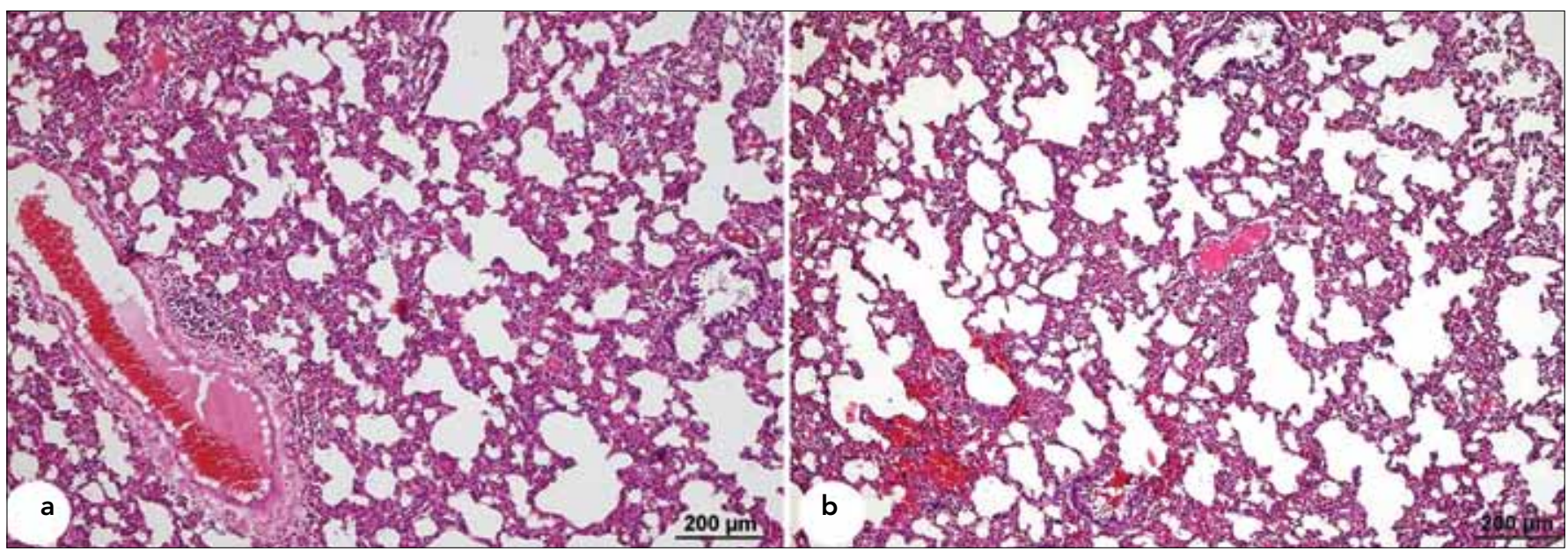

Figure 3. a, b. Histopathological HE staining of samples from the pre-OA- $\alpha$-LA group. Perivascular interstitial infiltration by mononuclear cells (a). Perivascular interstitial infiltration by mononuclear cells, with mild haemorrhage (b).

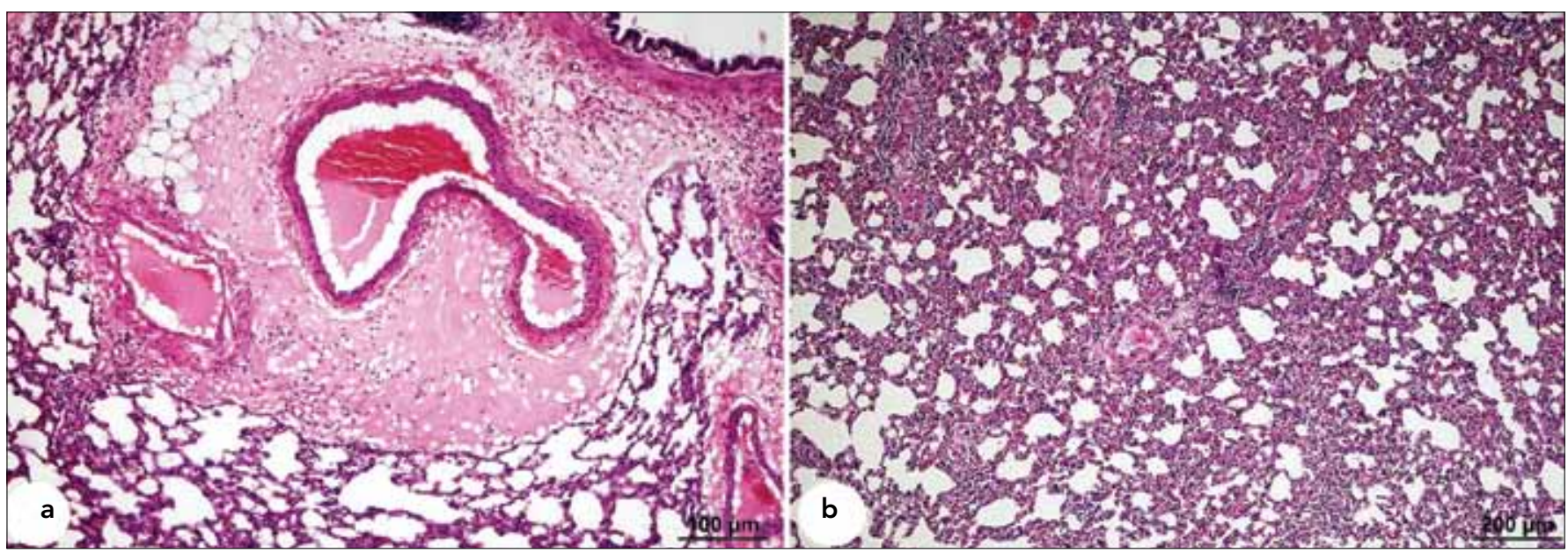

Figure 4. a, b. Histopathological HE staining of samples from the post-OA- $\alpha$-LA group. Vascular permeability increase, perivascular oedema, and hyaline membrane formation (a). Interstitial intra-alveolar infiltration by mononuclear cells (b). 
Samples from the post-OA- $\alpha$-LA group developed a severe increase in vascular permeability. Diffuse alveolar damage including interstitial intra-alveolar mononuclear cell infiltration was also present in these samples (Figure $4 a$ and $4 b$ ).

\section{Discussion}

Previous research has established that ARDS increases oxidative stress and secretion of ROS from the neutrophils of patients (25-30). Studies involving the experimental induction of $A L I$ as a model for ARDS have reported increased MDA concentration, indicating increased oxidative stress and altered activity of antioxidant enzymes (15, 31-33). Additional research has revealed that the plasma of patients with ARDS contains reduced levels of antioxidants and that neutrophil infiltration and ROS accumulation can exhaust the total antioxidant capability of the lungs $(26,30)$.

$\alpha$-LA is a strong antioxidant and a potential therapeutic for many diseases, particularly those associated with oxidative stress. The antioxidant activity of $\alpha$-LA may be the result of its abilities to both scavenge ROS and restore the capability of endogenous antioxidants, such as vitamin $C$, vitamin $E$, and GSH $(13,14)$. $\alpha$-LA has been shown by many studies, both in vivo and in vitro, to decrease lipid peroxidation levels. Reduced lipid peroxidation following $\alpha$-LA administration has been observed to be associated with a protective effect against adriamycin-induced nephrotoxicity and cardiotoxicity in rats $(34,35)$. Additional studies have found that $\alpha$-LA treatment results in a decreased MDA level in the plasma (36), liver, kidney (17) and different regions of the brain (37).

Many studies have investigated the effects of $\alpha$-LA on antioxidant enzymes $(35,36)$. Maritim et al. (38) reported that $\alpha$-LA administration reduced oxidative stress and altered SOD, CAT, and GSH-Px enzymatic activity levels in the liver, kidney, and heart in rats. Similarly, Shila et al. (39) showed that treatment with $\alpha$-LA resulted in decreased oxidant production and lipid peroxidation in the brain, whereas it led to increased levels of enzymatic activity for SOD, CAT, and GSH-Px in all brain regions.

In this study, serum samples from the OA group contained a greater amount of MDA than samples from the control group $(p<0.001)$. Notably, the serum MDA level was lower in the pre-OA- $\alpha$-LA samples compared with that in the OA samples; suggesting oxidative stress preventive effects of $\alpha$-LA. These results imply that $A L I$ increases oxidative stress and that $\alpha$-LA exhibits an opposing effect protecting against ALI. The absence of a significant difference in the serum MDA level between the post-OA- $\alpha-L A$ and OA groups suggests that the administered dose of $\alpha$-LA is insufficient to produce an injuryreversing effect.

As a result of the examination of the $\alpha$-LA samples, it was determined that the increased activity levels of CAT and GSH-Px and elevated serum GSH content are likely caused by the strong antioxidant properties of $\alpha$-LA and its restorative effect on endogenous antioxidants. Conversely, with the OA samples, the decreased enzymatic activity levels and GSH concentration indicate a pro-oxidant shift in the oxidantantioxidant balance during OA-induced ALI. The conclusions drawn from a comparison of pre-OA- $\alpha$-LA samples with OA samples suggest that the $\mathrm{OA}$-induced increase in oxidative potential was counteracted by $\alpha$-LA; in fact, antioxidant capability appeared to recover until it approximated that in control samples. However, in post-OA- $\alpha$-LA samples, the increase in oxidative stress resulting from injury was not neutralised by $\alpha$-LA. Taken together, these findings suggest that $\alpha$-LA exerts preventive effects only if it is administered prior to the induction of an injury.

OA is commonly used to induce ALI in laboratory animals. Exposure to OA has been previously shown to result in alveolar oedema, congestion, neutrophil infiltration, and deterioration of the pulmonary structure in the lung tissue of rats $(33,15)$. Similarly, neutrophil infiltration, alveolar oedema, and expansion and thickening of the alveolar wall have been reported in an experimental lung injury model for acute pancreatitis (40). In the current study, rats exposed to OA experienced $\mathrm{ALI}$ characterised by similar problems: perivascular oedema, interstitial and intra-alveolar oedema, mononuclear cell infiltration, haemorrhage, hyaline membrane formation, and diffuse alveolar damage. Prominent histopathological changes observed in samples from the OA group, such as increased vascular permeability, oedema, and hyaline membrane formation, were less severe or absent in pre-OA- $\alpha$-LA samples. The histopathological examination and supporting biochemical analyses confirmed the presence of OA-induced $A L I$ and the protective effects of an $\alpha$-LA infusion prior to exposure to $O A$.

In conclusion, the application of OA to develop an experimental ALI model resulted in oxidative stress characterised by elevated serum MDA concentrations and decreased levels of activity for the antioxidant enzymes GSH-Px, SOD, and CAT. Exposure to OA also produced histopathological damage in the lung tissue of rats. However, if $\alpha$-LA was administered 15 minutes before $\mathrm{OA}$ infusion, oxidative stress was reduced, which was indicated by lower serum MDA content, increased levels of antioxidant enzymatic activity, and amelioration of histopathological damage to the lungs of rats. In summary, we conclude that $\alpha$-LA protects against and may prevent ALI.

Ethics Committee Approval: Ethics committee approval was received for this study from the local ethics committee of Firat University Medical Faculty.

\section{Informed Consent: N/A.}

Peer-review: Externally peer-reviewed.

Author contributions: Concept - M.F.G., M.H.M.; Design - M.F.G., M.H.M., F.G.B.; Supervision - M.F.G., F.G.B.; Resource - M.F.G., F.G.B.; Materials F.G.B., i.Y., Ö.B., F.S.; Data Collection\&/or Processing - F.G.B., i.Y., Ö.B., F.S.; Analysis\&/or Interpretation - F.G.B., I.Y., Ö.B., F.S.; Literature Search - F.G.B., F.S.; Writing - F.G.B., F.S.; Critical Reviews - M.F.G., M.H.M., F.G.B.

Conflict of Interest: No conflict of interest was declared by the authors.

Financial Disclosure: This study was supported by the Firat University Scientific Research Projects Unit (FUBAP), project number 1402.

\section{References}

1. Repine JE. Scientific perspectives on adult respiratory distress syndrome. Lancet 1992;339:466-9. [CrossRef] 
2. Artigas A, Bernard GR, Carlet J, Dreyfuss D, Gattinoni L, Hudson $\mathrm{L}$, et al. The American-European Consensus Conference on ARDS, part 2: Ventilatory, pharmacologic, supportive therapy, study design strategies, and issues related to recovery and remodeling. Acute respiratory distress syndrome. Am J Respir Crit Care Med 1998;157:1332-47. [CrossRef]

3. Tasaka S, Hasegawa N, Ishizaka A. Pharmacology of acute lung injury. Pulm Pharmacol Ther 2002;15:83-95. [CrossRef]

4. Bernard GR, Artigas A, Brigham KL, Carlet J, Falke K, Hudson L, et al. The American-European Consensus Conference on ARDS. Definitions, mechanisms, relevant outcomes, and clinical trial coordination. Am J Respir Crit Care Med 1994;149:818-24. [CrossRef]

5. Tzouvelekis A, Pneumatikos I, Bouros D. Serum biomarkers in acute respiratory distress syndrome an ailing prognosticator. Respir Res 2005;6:62. [CrossRef]

6. Bellingan GJ. The pulmonary physician in critical care *6: The pathogenesis of ALI/ARDS. Thorax 2002;57:540-6. [CrossRef]

7. van $\operatorname{der}$ Vliet $A$, Cross CE. Oxidants, nitrosants, and the lung. Am J Med 2000;109:398-421. [CrossRef]

8. Griesenbach U, Scheid P, Hillery E, de Martin R, Huang L, Geddes $\mathrm{DM}$, et al. Anti-inflammatory gene therapy directed at the airway epithelium. Gene Ther 2000;7:306-13. [CrossRef]

9. Zhou ZH, Sun B, Lin K, Zhu LW. Prevention of rabbit acute lung injury by surfactant, inhaled nitric oxide and pressure support ventilation. Am J Respir Crit Care Med 2000;161:581-8. [CrossRef]

10. Neumann P, Berglund JE, Anderson LG, Maripu E, Magnusson A Hedenstierna $G$. Effects of inverse ratio ventilation and positive end-expiratory pressure in oleic acid-induced lung injury. Am J Respir Crit Care Med 2000;161:1537-45. [CrossRef]

11. Köksel O, Tamer L, Özdülger A, Erçil M, Ercan B, Kanık A. The effect of $\mathrm{N}$-acetylcystein on the increase of nitric oxide metabolites observed in oleic acid-induced acute lung injury. T Klin J Med Sci 2004;24:323-7.

12. Golbidi S, Moriuchi H, Yang C, Irikura M, Irie T, Hamasaki N. Preventive effect of phosphoenolpyruvate on hypoxemia induced by oleic acid in Guinea pigs. Biol Pharm Bull 2003;26:336-40. [CrossRef]

13. Navari-Izzo F, Quartacci MF, Sgherri C. Lipoic acid: a unique antioxidant in the detoxification of activated oxygen species. Plant Physiol Biochem 2002;40:463-70. [CrossRef]

14. Packer L, Witt EH, Tritschler HJ. Alpha-lipoic acid as a biological antioxidant. Free Radic Biol Med 1995;19:227-50. [CrossRef]

15. Koksel O, Cinel I, Tamer L, Cinel L, Ozdulger A, Kanik A, et al. $\mathrm{N}$-acetylcysteine inhibits peroxynitrite-mediated damage in oleic acid-induced lung injury. Pulm Pharmacol Ther 2004;17:263-70. [CrossRef]

16. Hilkner-Silva M, Leme AS, Arantes-Costa FM, Saldiva PHN, Lichtenstein A, Martins MA. Effects of mannitol on the acute lung injury induced by oleic acid in rats. Shock 2001;16:415-8. [CrossRef]

17. Arivazhagan P, Panneerselvam SR, Panneerselvam C. Effect of DL-alpha-lipoic acid on the status of lipid peroxidation and lipids in aged rats. J Gerontol 2003;58:788-91. [CrossRef]

18. Satoh K. Serum lipid peroxide in cerebrovascular disorders determined by a new colorimetric method. Clin Chim Acta 1978;90:37-43.

19. Yagi K. Assay of lipid peroxidation in blood plasma or serum. Methods Enzymol 1984;105:328-31. [CrossRef]

20. Durak I, Yurtarslan Z, Canbolat O, Akyol O. A methodological approach to superoxide dismutase (SOD) activity assay based on inhibition of nitroblue tetrazolium (NBT) reduction. Clin Chim Acta 1993;214:103-4. [CrossRef]
21. Sun Y, Oberley LW, Li Y. A simple method for clinical assay of superoxide dismutase. Clin Chem 1988;34:497-500.

22. Aebi $\mathrm{H}$. Catalase in vitro assay methods. Methods Enzymol 1984;105:121-6. [CrossRef]

23. Paglia De Valentine W. Studies on the quantitative and qualitative characterisation of erytrocyte glutathione peroxidase. J Lab Clin Med 1967;70:158-9.

24. Ellman G. Tissue sulphydryl groups. Arch Biochem Biophys 1959;82:70-7. [CrossRef]

25. Yang C, Moriuchi H, Takase J, Ishitsuka Y, Irikura M, Irei T. Oxidative stress in early stage of acute lung injury induced with oleic in guinea pigs. Biol Pharm Bull 2003;26:424-8. [CrossRef]

26. Metnitz PG, Bartens $C$, Fischer M, Fridrich $P$, Steltzer $H$, Druml W. Antioxidant status in patients with acute respiratory distress syndrome. Intensive Care Med 1999;20:180. [CrossRef]

27. Chabot F, Mitchell JA, Gutteridge JMC, Evans TW. Reactive oxygen species in acute lung injury. Eur Respir J 1998;11:745-57.

28. MacNee W. Oxidants/antioxidants and chronic obstructive pulmonary disease: pathogenesis to therapy. Novartis Found Symp 2001;234:169-85. [CrossRef]

29. Liu H, Zhang D, Zhao B, Zhao J. Superoxide anion, the main species of ROS in the development of ARDS induced by oleic acid. Free Radic Res 2004;38:1281-7. [CrossRef]

30. Zhang H, Slutsky AS, Vincent JL. Oxygen free radicals in ARDS, septic shock and organ dysfunction. Intensive Care Med 2000;26:474-6. [CrossRef]

31. Zhang JY, Ding CH, Ling YL, Dong CF, Tan JQ, Xian XH. Inhibitory effect of melatonin on the expression of nuclear factor-KappaB during acute lung injury in rats. Zhongguo Wei Zhong Bing Ji Jiu Yi Xue 2008;20:604-6.

32. Turut $H$, Kurutas EB, Bulbuloglu E, Yasım A, Ozkaya M, Onder A, et al. Zinc aspartate alleviates lung injury induced by intestinal ischemia-reperfusion in rats. J Surg Res 2009;151:62-7. [CrossRef]

33. Koksel O, Kaplan MB, Ozdulger A, Tamer L, Degirmenci U, Cinel $L$, et al. Oleic acid-induced lung injury in rats and effects of caffeic acid phenethyl ester. Exp Lung Res 2005;31:483-96. [CrossRef]

34. Malarkodi KP, Balachandar AV, Varlakshmi P. The influence of lipoic acid on adriamycin-induced hyperlipidemic nephrotoxicity in rats. Mol Cell Biochem 2003;247:139-45. [CrossRef]

35. Balachandar AV, Malarkodi KP, Varlakshmi P. Protective role of DL-alpha-lipoic acid against adriamycin-induced cardiac lipid peroxidation. Hum Exp Toxicol 2003;22:249-54. [CrossRef]

36. Arivazhagan $P$, Juliet $P$, Panneerselyam $C$. Effect of dl-alpha-lipoic acid on the status of lipid peroxidation and antioxidants in aged rats. Pharmacol Res 2000;41:299-303. [CrossRef]

37. Arivazhagan $P$, Thilakavathy $T$, Ramanathan $K$, Kumaran S, Panneerselyam C. Effect of DL-alpha-lipoic acid on the status of lipid peroxidation and protein oxidation in various brain regions of aged rats. J Nutr Biochem 2002;13:619-24. [CrossRef]

38. Maritim AC, Sanders RA, Watkins JB. Effects of alpha-lipoic acid on biomarkers of oxidative stress in streptozotocin-induced diabetic rats. J Nutr Biochem 2003;14:288-94. [CrossRef]

39. Shila S, Kokilavani V, Subathra M, Panneerselyam C. Brain regional responses in antioxidant system to alpha-lipoic acid in arsenic intoxicated rat. Toxicology 2005;210:25-36. [CrossRef]

40. Gultekin FA, Kerem M, Tatlicioglu E, Aricioglu A, Unsal C, Bukan $N$. Leptin treatment ameliorates acute lung injury in rats with cerulein-induced acute pancreatitis. World J Gastroenterol 2007;13:2932-8 